This is the author's final, peer-reviewed manuscript as accepted for publication. The publisher-formatted version may be available through the publisher's web site or your institution's library.

\title{
Putting QR codes to the test
}

Leo Lo, Jason Coleman, Danielle Theiss

\section{How to cite this manuscript}

If you make reference to this version of the manuscript, use the following information:

Lo, L., Coleman, J., \& Theiss, D. (2013). Putting QR codes to the test. Retrieved from http://krex.ksu.edu

\section{Published Version Information}

Citation: Lo, L., Coleman, J., \& Theiss, D. (2013). Putting QR codes to the test. New Library World, 114(11/12), 459-477.

Copyright: @ Emerald Group Publishing Limited

Digital Object Identifier (DOI): doi:10.1108/NLW-05-2013-0044

Publisher's Link:

http://www.emeraldinsight.com/journals.htm?articleid=17100242\&show=abstract

This item was retrieved from the K-State Research Exchange (K-REx), the institutional repository of Kansas State University. K-REx is available at http://krex.ksu.edu 


\section{Putting QR Codes to the Test}

\section{Introduction}

A QR code (Quick Response code) is a matrix bar code or two-dimensional code originally designed and released by Denso Wave Incorporated in 1994. It was adopted by the Japanese auto industry for use in their production management systems communication to track parts in vehicle manufacturing (Denso Wave Incorporated).

Unlike conventional barcodes that store information in a horizontal manner, QR codes can store information both horizontally and vertically. Therefore, the amount of information that QR codes can store is much greater than conventional barcodes.

The information encoded in the code may be text, a URL, or other data, and can be read by mobile device cameras. With the increased popularity of smartphones, the applications of QR codes have also expanded. QR codes are now being used in commercial tracking, entertainment and transport ticketing, product/loyalty marketing, in-store product labeling, among many other usages.

Comscore's study (2011) found that "20.1 million mobile phone owners in the U.S. used their device to scan a QR code in the three-month average period ending October 2011”. Among these mobile users who used their phone to scan a QR code, the highest percentage (59.4\%) did so from home. Another Comscore study (2012) reveals that "more than half of the smartphone audience that scanned a QR/bar code did so from a printed magazine or newspaper (50.9 percent), making it the most popular source.”

According to Pulliam and Landry (2010: 68), the advantages of using QR codes include:

- QR is dynamic. If a QR code is linked to a URL, and the URL changes, you can revise the underlying data without having to alter the code's image.

- $\mathrm{QR}$ is freely available.

- QR is an ISO (International Organization for Standardization) standard.

- QR is well-designed, with a higher capacity than other matrix codes. QR also sports great size variability and error correction capabilities. Up to $30 \%$ of damaged or obscured data can be restored.

- QR is enriching-QR codes tie the physical to the digital. They also can deliver content with a great depth of interactivity.

\section{Popular Uses of QR Codes outside of Libraries}

Many airlines are now using QR codes to store boarding pass information, which can be emailed to a personal mobile device or laptop computer, and in turn can be scanned at each check point and at the gate terminal before boarding. A German toy store company, MyToys.de, used QR 
codes creatively and successfully for their LEGO campaign in 2009. "To advertise LEGO and drive sales, they created hand-made, three-dimensional QR codes out of real LEGOs. [...] To find out what they were, people could shoot the codes with their phones. This would "break" the code, they would be told what the picture was, and they would receive a link to the store where they could purchase the box of the same LEGOs used to create the code [...], and compared to the non-advertised Lego products on the site, twice as many boxes were sold” (Barber, 2009). This was a hugely successful campaign and resulted in sales of boxes of LEGO doubling. The campaign also won an award at the 2009 Cannes Lion International Advertising Awards for interactivity (Elmore \& Stephens, 2012).

\section{Libraries and QR codes}

Wisniewski stated that "until recently, the only initiatives librarians have taken to bring these worlds [physical and online] together is to advertise their library's website in the physical space or to encourage users of virtual services that the physical space is open, welcoming, and full of great stuff to explore” (2010: 55). QR codes are one way to bridge that digital divide. As mobile devices become more popular among library users, the interest of using QR codes in academic libraries has also grown in recent years. A number of libraries have begun experimenting with the technology.

Here are some of the popular uses of QR codes in libraries:

- Library audio tour (Whitchurch, 2012)

- Group Study Room Scheduler (Whitchurch, 2012)

- Marketing/Promotional Materials (Whitchurch, 2012) (Hampton et al.,2012)

- Linking from print to electronic journal holdings (Walsh, 2011)

- Providing an electronic alternative to physical books (Walsh, 2011)

- Promoting online audiovisual materials (Walsh, 2011)

- Embedding video help (Walsh, 2011)

- Bringing external resources into the library (Walsh, 2011)

- Finding appropriate help (Walsh, 2011)

- Taking the catalogue record with you (Walsh, 2011) (Hampton et al., s 2012)

- $\quad$ Linking fromcourse syllabi (MacDonald, 2012)

\section{Rockhurst University Library and QR codes}

Rockhurst University Library uses QR codes to promote its events and services, advertise the hours for the library, share how to find the Ask a Librarian chat service, and promote library exhibits. Other applications being considered include use of QR codes to link to an online survey, a song or video or to make library study room reservations.

QR codes can be added to OPACs to facilitate the delivery of item specific information regarding a book title, where it is located, and call number information allowing the patron the ability to use his or her own smartphone, or another QR code enabled device, to capture the 
relevant information needed to retrieve the item from the circulation stacks. The image below (Figure 1) is a screenshot of Rockhurst University's Millennium catalog (Innovative Interfaces) with the QR code on the far right side of the screen. During the spring of 2011, Danielle Theiss, the Head of Technical Services at Rockhurst University Library approached the MOBIUS Consortium, a 68 academic, public and special library system collaborative in the state of Missouri, to inquire if QR codes could be implemented within its local catalog. Jessica Hammond, a Library Support Representative for MOBIUS, worked with Theiss over the summer of 2011 to implement this feature.

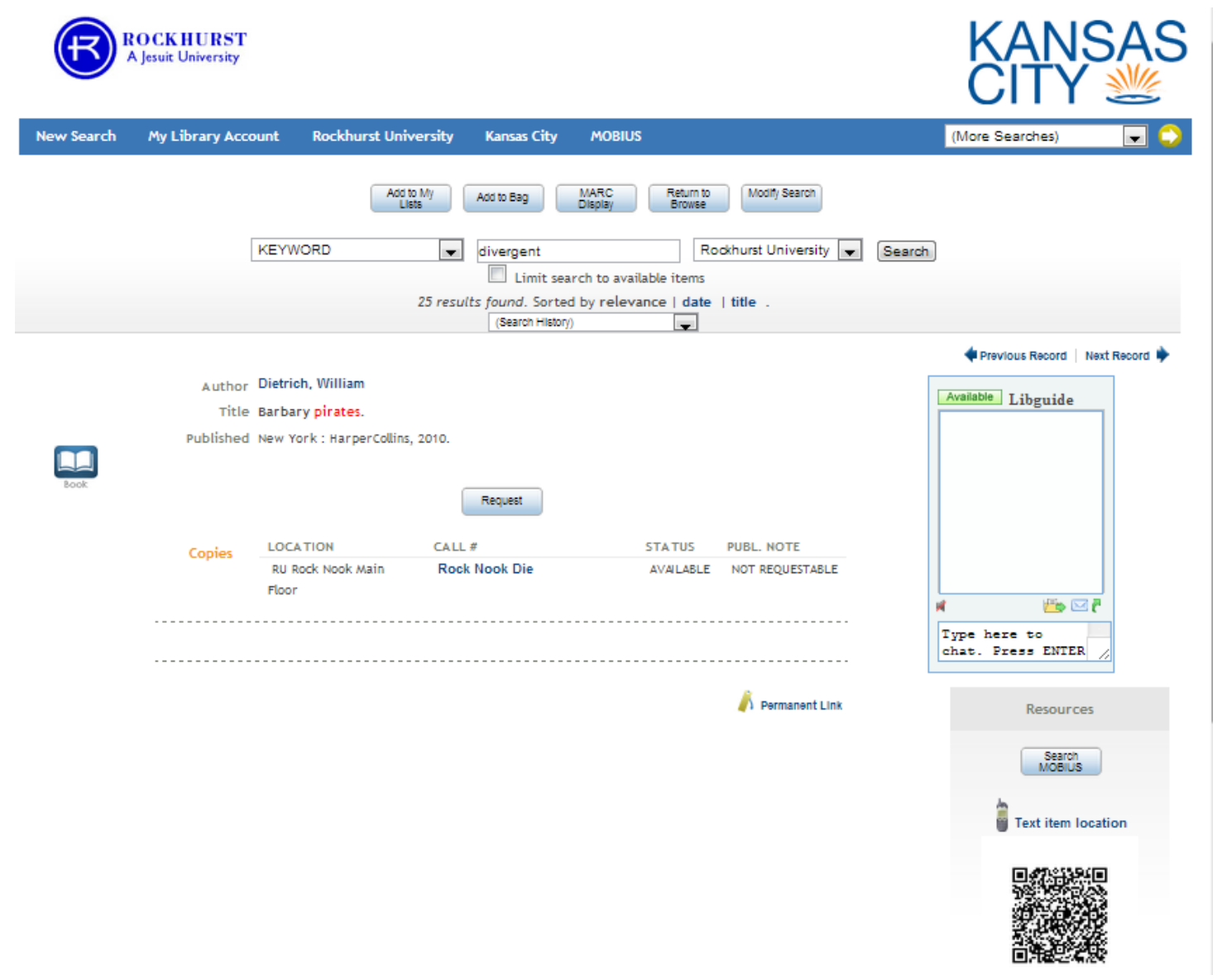

[Figure 1. "Screenshot of a record from Rockhurst University’s catalog.”]

\section{Assessment}

While there are many QR codes projects initiated at various libraries, assessment is generally limited to tracking the usage data via customized URLs. Shin et al. (2012) found that user intentions and behaviors are largely influenced by the perception of the quality of QR codes. In addition, the results of the model showed that interactivity is a key behavioral antecedent to the use of QR codes. However, qualitative studies on QR code user preferences or QR code 
performance, especially related to library users, are few and far between. Therefore, librarians at Kansas State University Libraries initiated a pilot project to investigate this aspect of QR codes usage.

\section{Methods}

In January 2011 a QR Codes Task Force was formed at Kansas State University Libraries and charged with assessing the likelihood that the Libraries' patrons would make use of QR codes if they were deployed. The Task Force conducted two studies in April and May of 2011: a short survey and a pilot investigation. In October 2011, two of the authors, Leo Lo and Jason Coleman, convened five focus groups to gain further insight into patrons' preferences for QR code design as well as data about their potential benefits. Institutional Review Board approval was granted for each of the studies.

\section{Study 1: Survey}

The main goals of the survey were to learn whether patrons find it easy to use a QR code, to gather patrons' opinions about several possible library uses for QR codes, and to solicit additional ideas for using QR codes in libraries. To achieve these goals, the task force created an eight item survey using Google Forms, a mobile friendly platform. The eight items are shown below. For the full survey, see Appendix 1.

1. On a scale of 1 to 5 , with 1 being very easy, rate how easy it was for you to get to this page via this QR code.

2. Were there any challenges to using this QR code? If yes, please explain.

For questions 3-7. On a scale of 1 to 5, with 1 being "love it" and 5 being "hate it", please rate each of the following ideas for how K-State Libraries could use QR codes

3. On DVD cases - link to movie trailers

4. On equipment (e.g., microform machines) - link to tutorials on how to use them

5. In various library locations: link to self-guided library tour

6. On self-checkout machines - link to your library account

7. On stacks/books/journals - link to related digital resources

8. Any other comments or suggestions about how K-State Libraries should use (or not use) QR codes?

Because one goal was to gauge how easy patrons find it to use QR codes, the task force opted to require that patrons actually scan a QR code to access the survey. The Libraries' Graphic Design Specialist and Web Services Librarian created a website button as well as signs and handouts with the QR code and brief instructions for using the code.

The survey was made available through a QR code button displayed on the K-State Libraries' home page from April 25, 2011 through May 6, 2011. It was also made available through printed 
QR codes on two large signs (one in Hale Library's 24 hour study center and one near its main entrance) and on 200 small handouts in holders attached to the signs. The signs and handouts were available from April 25, 2011 through May 15, 2011. The design of the large sign is shown in Figure 2.

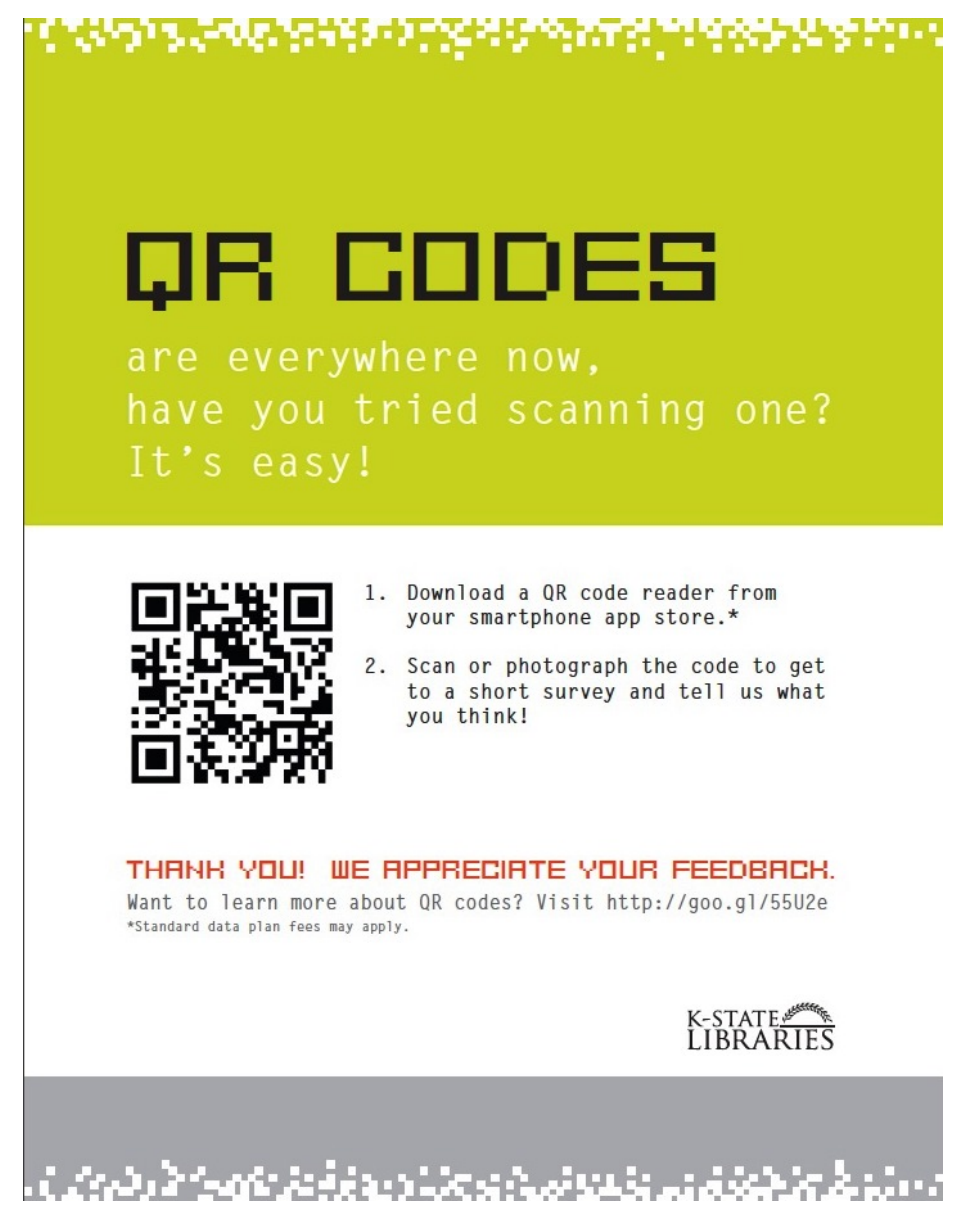

[Figure 2.“Sign inviting patrons to participate in a QR code survey.”]

\section{Study 2: QR code sign pilot}

In addition to gathering thoughts and opinions about QR codes, the task force implemented a small-scale pilot to learn whether the Libraries' patrons would make use of QR codes. Although they discussed a number of potential applications of QR codes, they ultimately decided to use only three: a QR code leading to a map of Hale Library, a QR code leading to a mobile-friendly stacks guide, and a QR code leading to a mobile friendly portal to several methods for obtaining help. They placed all three QR codes on a single 8.5” x 11" sign and added a short url below each QR code so patrons would not be required to scan the code to benefit from the sign. The sign design is shown in Figure 3. 


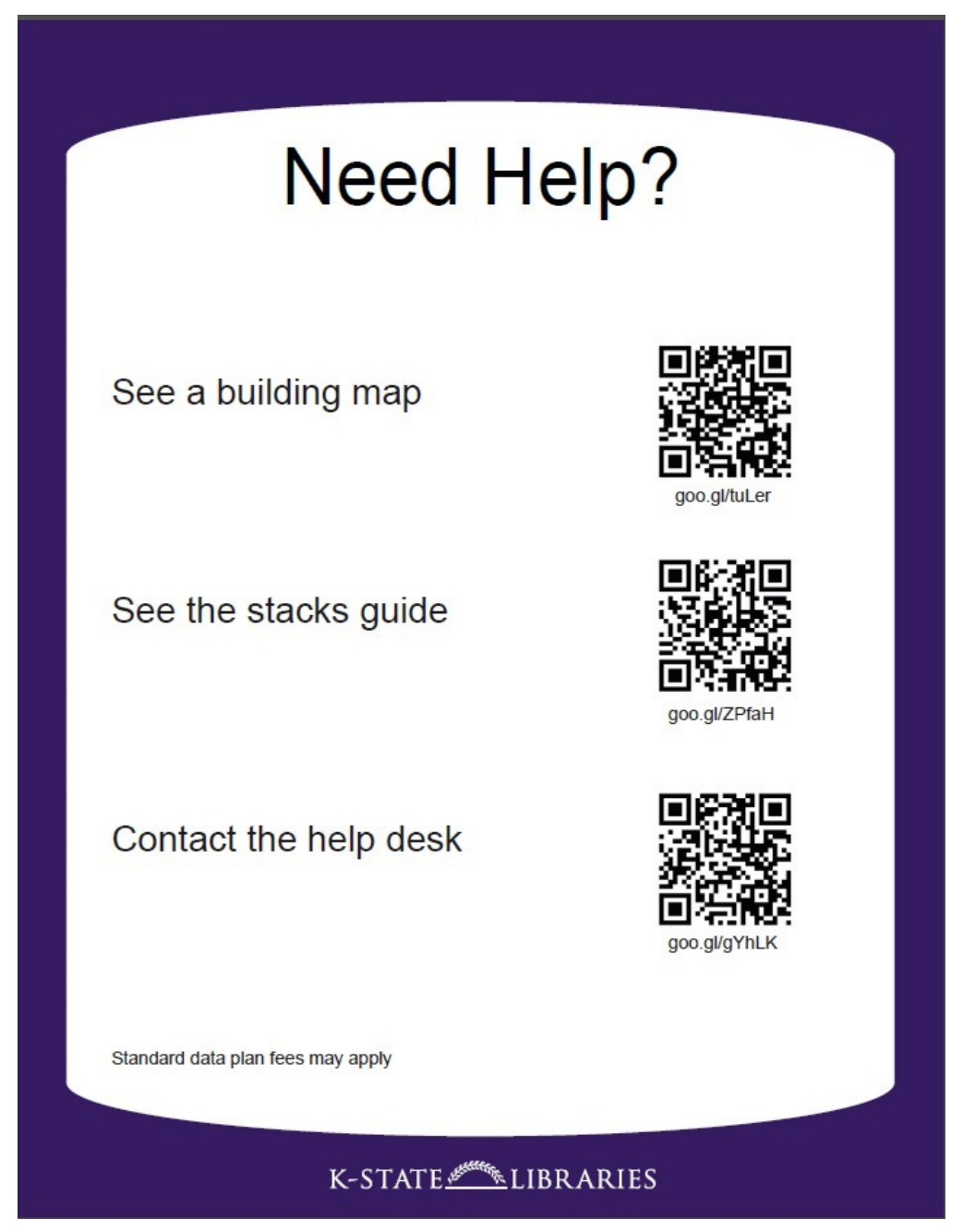

[Figure 3. "Sign used for the QR code pilot study"]

Rather than create only one or two copies of the sign and hope that patrons would see and use the QR codes contained therein, the task force created 40 copies of the sign and distributed them throughout the stacks, near scanners, at current and former help desks, in Hale Library's microforms room, and in elevators. To enable gathering of data about which codes or urls were used and where they were most frequently scanned, the task force created 3 unique QR codes and 3 unique urls for each of the 40 signs using Google's URL shortener, http://goo.gl. The task force then created a spreadsheet with the short url for each QR code and each text url and used goo.gl's tracking page for the short url to record the number of times that url was visited.

The 40 copies of the sign were displayed from April 25, 2011 through May 15, 2011.

\section{Study 3: Focus groups}

To augment the data gained from the first two studies, two members of the QR Codes Task Force, Leo Lo and Jason Coleman, held five separate focus groups during October, 2011. To 
recruit participants, Lo and Coleman composed the following e-mail message, which they asked instructors of several freshmen level courses to distribute to their students:

K-State Libraries is conducting freshmen focus groups in Room 114 in Hale library from $6 \mathrm{pm}-7 \mathrm{pm}$ on $\mathrm{X}$ and $\mathrm{X}$ dates. The purpose of the focus groups is to learn more about freshmen students' opinions of QR codes (two-dimensional barcodes). Pizza and cookies will be provided. If you are interested in participating, please write your e-mail address on the sign-up sheet. You will then be contacted by Jason Coleman from the library who will provide more detail.

In each focus group session, either Lo or Coleman assumed the role of facilitator and followed a written outline containing prompts and instructions. The person who was not facilitator served as note-taker. Each session was organized into the following eight segments:

Segment 1: Welcome and consent. In this segment, participants were encouraged to partake of pizza and cookies while they read the informed consent statement. After all participants finished reading the informed consent statement, the facilitator asked that all who wished to continue sign the statement. After all had signed (none of the participants in any of the focus groups withdrew), the facilitator introduced himself, provided a brief overview of what the session would entail, and asked the participants to introduce themselves.

Segment 2: QR code instructional session. The facilitator explained what a QR code is and demonstrated the process for scanning a code using a smartphone. He then explained that smartphones with QR codes would be provided and also offered to help participants download QR code readers to their smartphones if they wished to do so. This segment concluded with time for each participant to practice scanning a QR code that was provided to them.

Segment 3: QR code sign informational content preferences. The facilitator presented each participant with identical sets of four 8.5” x 11” QR code signs and asked the participants to examine each sign and turn them over when they were done. After each participant finished, the facilitator asked each to use a slip of paper to write down which sign they preferred. Once all participants had filled out a slip, the facilitator invited each to state which they had chosen and why.

Each sign used the same title ("Interested in Basketball? Check out our blog about the history of basketball here at K-State:”), same QR code, and same note (“*standard data plan fees may apply). The signs varied only in the nature of additional information presented on the sign. Sign 3a contained no additional information. Sign 3b contained a short url below the QR code. Sign 3c contained a long url below the QR code. Sign 3d contained a short url and the following instructions: "Scan this QR code to get this blog post 
on your mobile device. Don’t have a QR code reader? Download one from your app store.” Sign 3d is shown in Appendix Two.

Segment 4: QR code size preferences. This segment followed the same protocol as segment 3. In segment 4 each sign used the same title, long url, and note the participants had previously seen in segment 3 . The signs in segment 4 varied only in the size of the square QR code presented below the title. The length of each side of the code increased from 0.66 ” for sign 4 a to 1.04 ” for sign $4 \mathrm{~b}$ to 2.24 ” for sign 4 c to 3.27 ” for sign $4 d$.

Segment 5: QR code color preferences. This segment followed the same protocol as segments 3 and 4 . In segment 5 each sign used the same title, short url and note the participants had previously seen in segment 3. The signs in segment 5 varied only in the color of the square QR code presented below the title. Sign 5a showed a black and white QR code. In sign 5b the code was purple on a white background and in sign $5 c$ the code was gold on a purple background.

Segment 6: Timing study. The facilitator presented each participant with signs 3b, and 3c. He then instructed each participant to launch a QR code reader, wait for his signal and then scan the QR code on either sign and inform him when the target blog appeared on their phone. The facilitator started a digital timer when he told the participants to begin. As each participant stated they had finished, the facilitator wrote down the elapsed time. This protocol was then used to record how long it took each participant to type in the short url (http://goo.gl/4ZFMA) and view the blog and again to record how long it took each participant to type in the long url (http://ksulib.typepad.com/talking/2006/04/k-statekeepsak.html) and view the blog. For each of these url timing studies, the participants were instructed to launch a web browser and then wait for the signal to begin typing.

Segment 7: Questions. The facilitator posed a series of questions to the participants. He invited each participant to respond to each question in turn. The following questions were asked:

7a: Have you used QR codes previously?

7b: Can you think of activities in the library that you might want to do with QR codes?

7c: What do you think of the idea of the library using QR codes to provide a way for patrons to view DVD trailers? The sign would be posted near the DVD collection.

7d: What do you think of the idea of the library using QR codes to provide a way for patrons to call a librarian?

7e: What do you think of the idea of the library using QR codes to view videos showing how to use equipment such as a printer? 
7f: What do you think of the idea of the library using QR codes to provide a way for patrons to see a list of books related to the one whose QR code is scanned? The QR code would be displayed on the inside part of the book jacket.

7g: What do you think of the idea of the library using QR codes to provide a way to view maps showing how to get from the current location to various destinations? Each destination would have its own QR code.

7h: What do you think of the idea of the library using QR codes to provide a way for patrons to access a blog they could use to provide general feedback about the library? The code would be displayed on a sign near the entrance.

7i: How likely would you be to use QR codes in the library?

7j: Do you have any other suggestions or thoughts you would like to share with us?

Segment 8: Debriefing. The facilitator thanked each participant and explained that the information they shared would help the Libraries determine what types of QR codes to deploy and how to design them to be maximally effective. The facilitator closed by encouraging the participants to contact either Leo Lo or Jason Coleman if they have any questions about the study.

\section{$\underline{\text { Results }}$}

\section{Study 1: Survey}

The QR Codes Task Force received 28 survey responses during the three weeks the survey was open. Figure 4 shows the distribution of responses to the first question. A large majority of the responses, 25 (89\%) indicated that it was very easy to use the QR code. The subsequent question asking if the respondents experienced any challenges using the QR code elicited a total of seven replies: six indicating that no challenges were experienced and one stating that their device would not open the survey. 


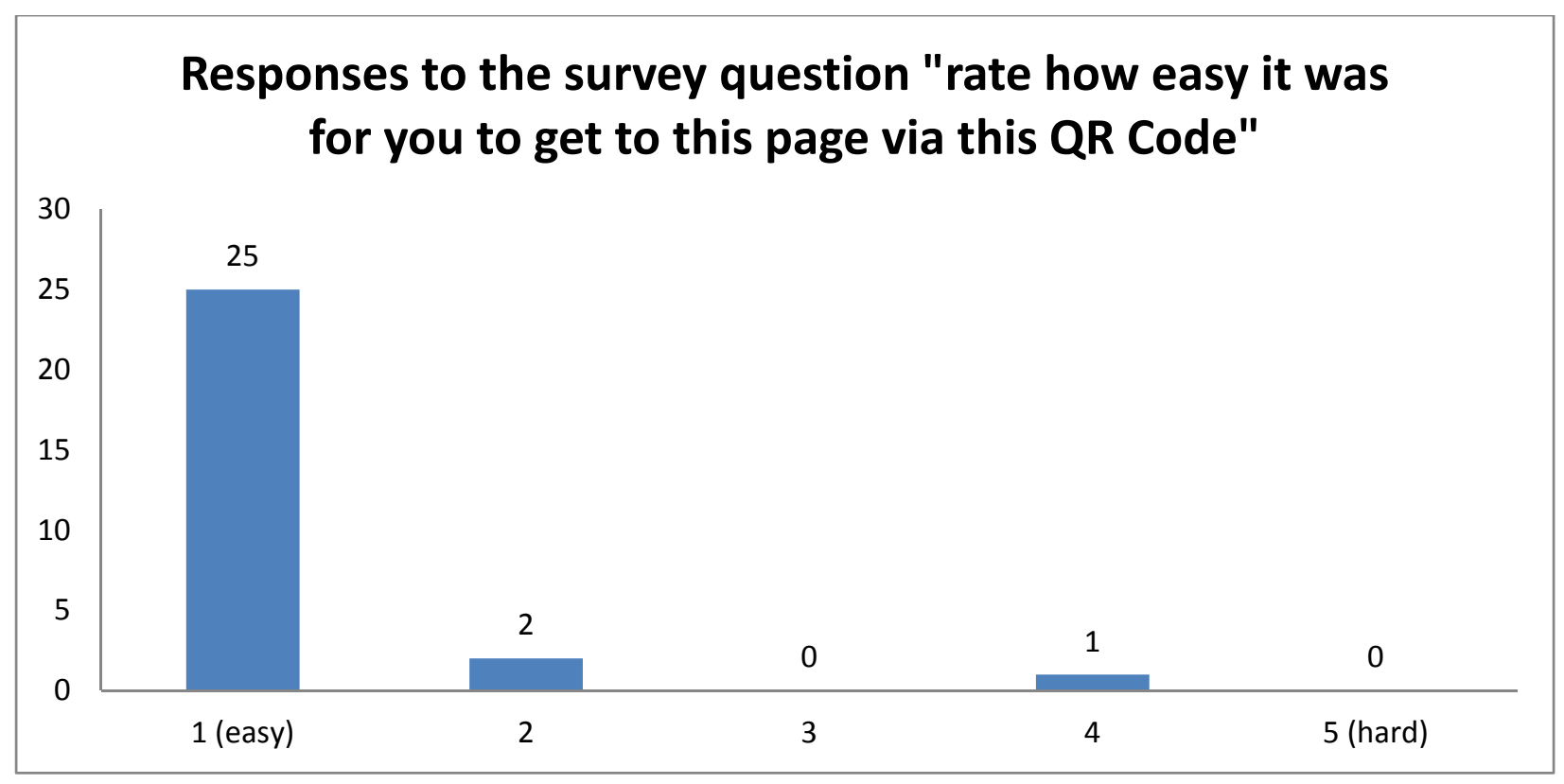

Figure 4

Each of the five ideas for QR code uses in libraries received a "love it” rating (a rating of 1 on the 5 point scale) by at least half of the respondents. Response distributions for each of these items are shown in Figures 5-9. Using average rating as a guide, the five proposed uses can be ranked in order as follows (most preferred use is listed first):

1. Using QR codes near self-check machines to link to “My Library Account” $(\bar{x}=1.15$, $\mathrm{n}=27$ )

2. Using QR codes on stacks/journals/books to link to related digital resources $(\bar{x}=1.37$, $\mathrm{n}=27$ )

3. Using QR codes on equipment (e.g., microforms) to link to tutorials on how to use them $(\bar{x}=1.52, \mathrm{n}=27)$

4. Using QR codes on DVD cases to link to movie trailers $(\bar{x}=1.56, \mathrm{n}=27)$

5. Using QR codes in various library locations to link to a self-guided tour $(\bar{x}=1.59, \mathrm{n}=27)$

In response to our question soliciting comments and ideas about how K-State Libraries should use QR codes only one substantive reply was given. That response was a suggestion to use QR codes as a way to facilitate checking in on services like Foursquare. 


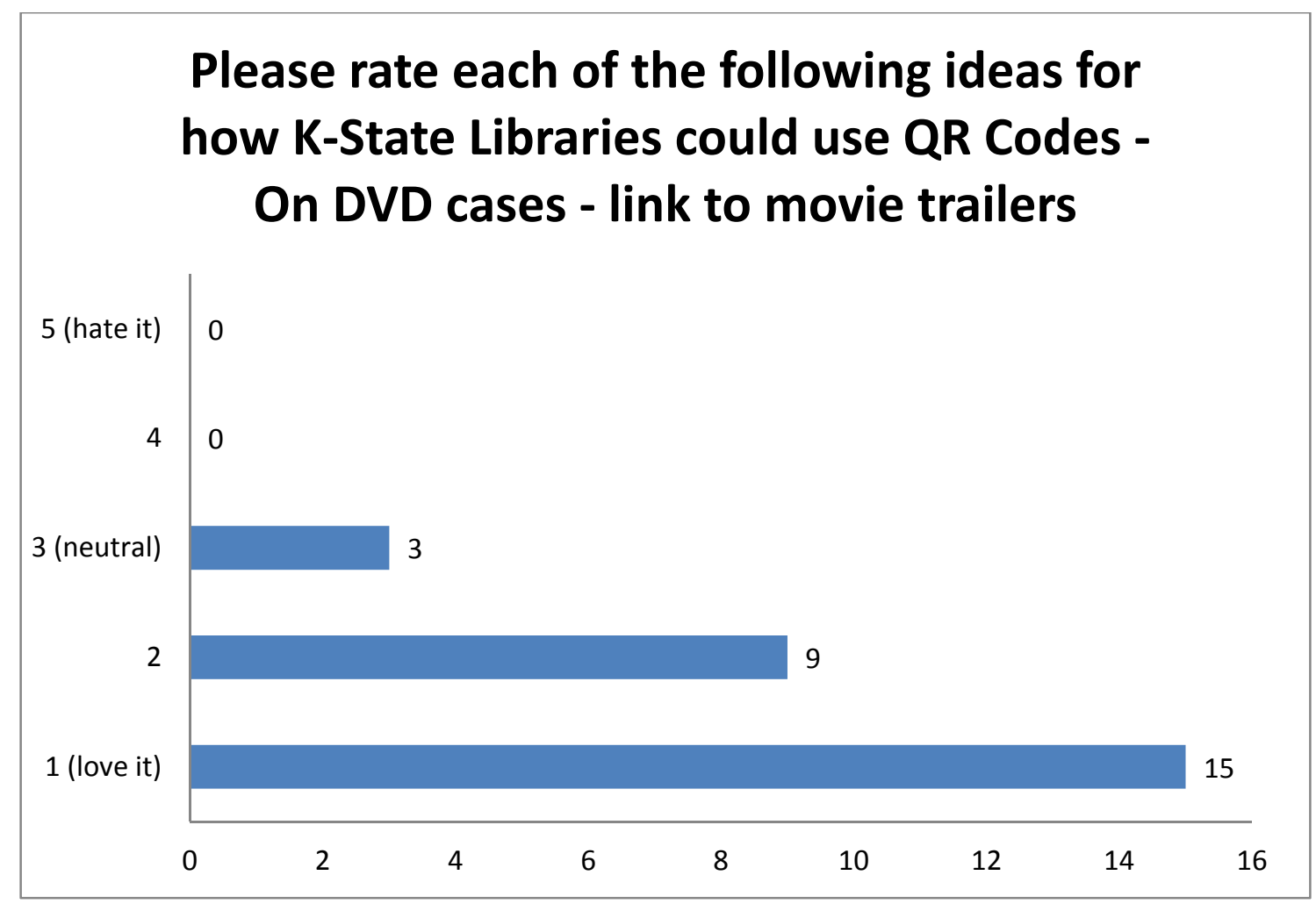

Figure 5

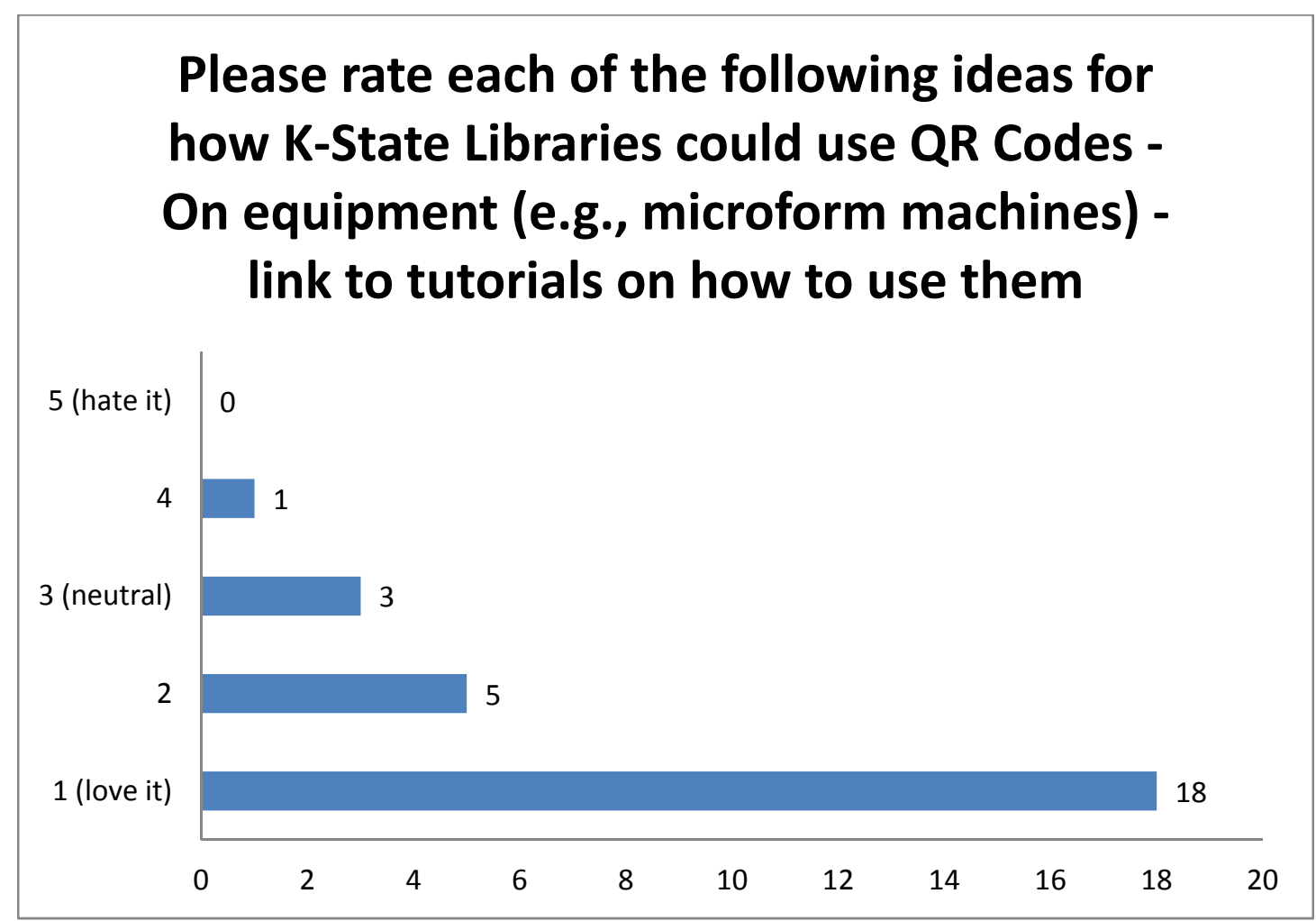

Figure 6 


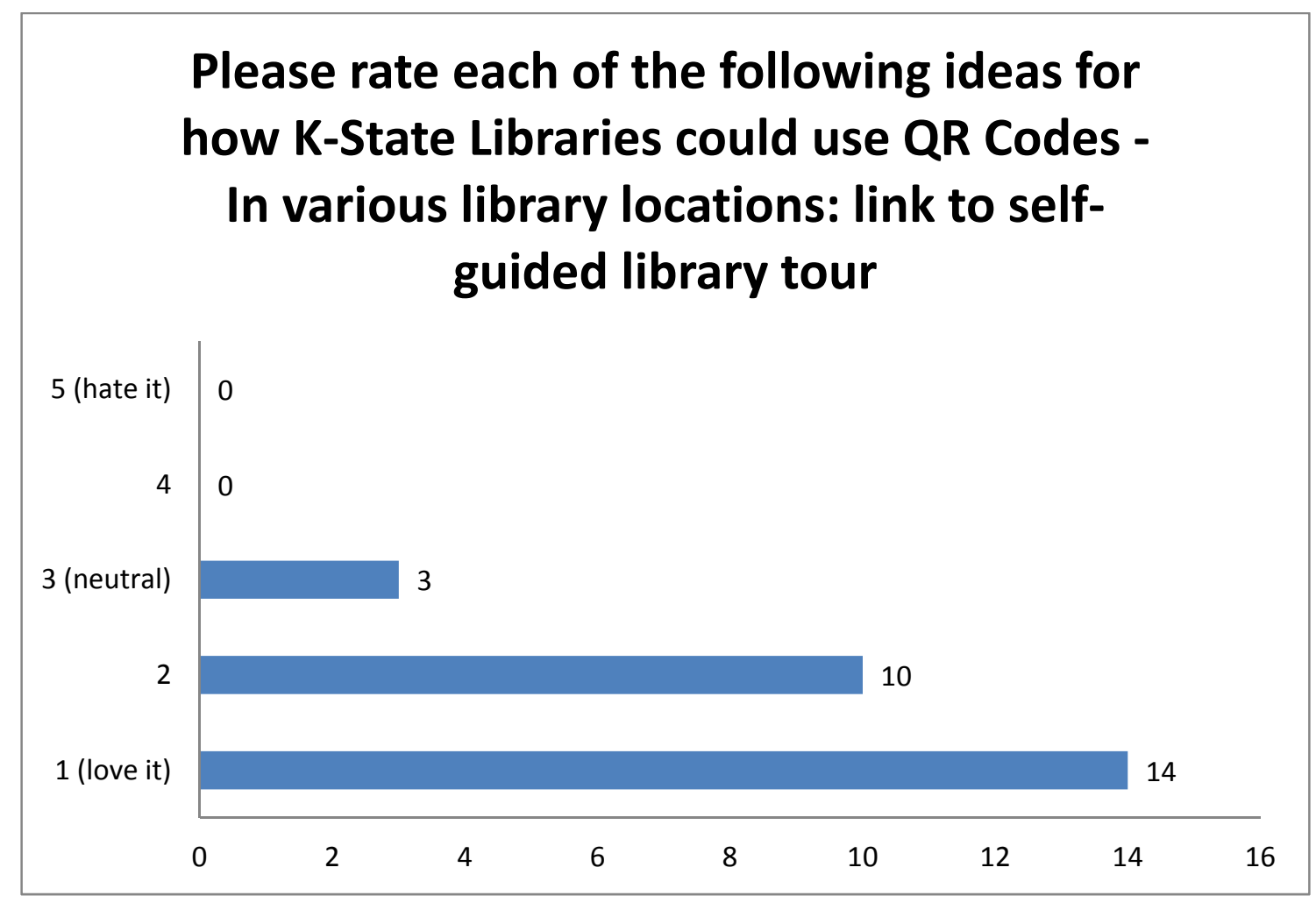

Figure 7 


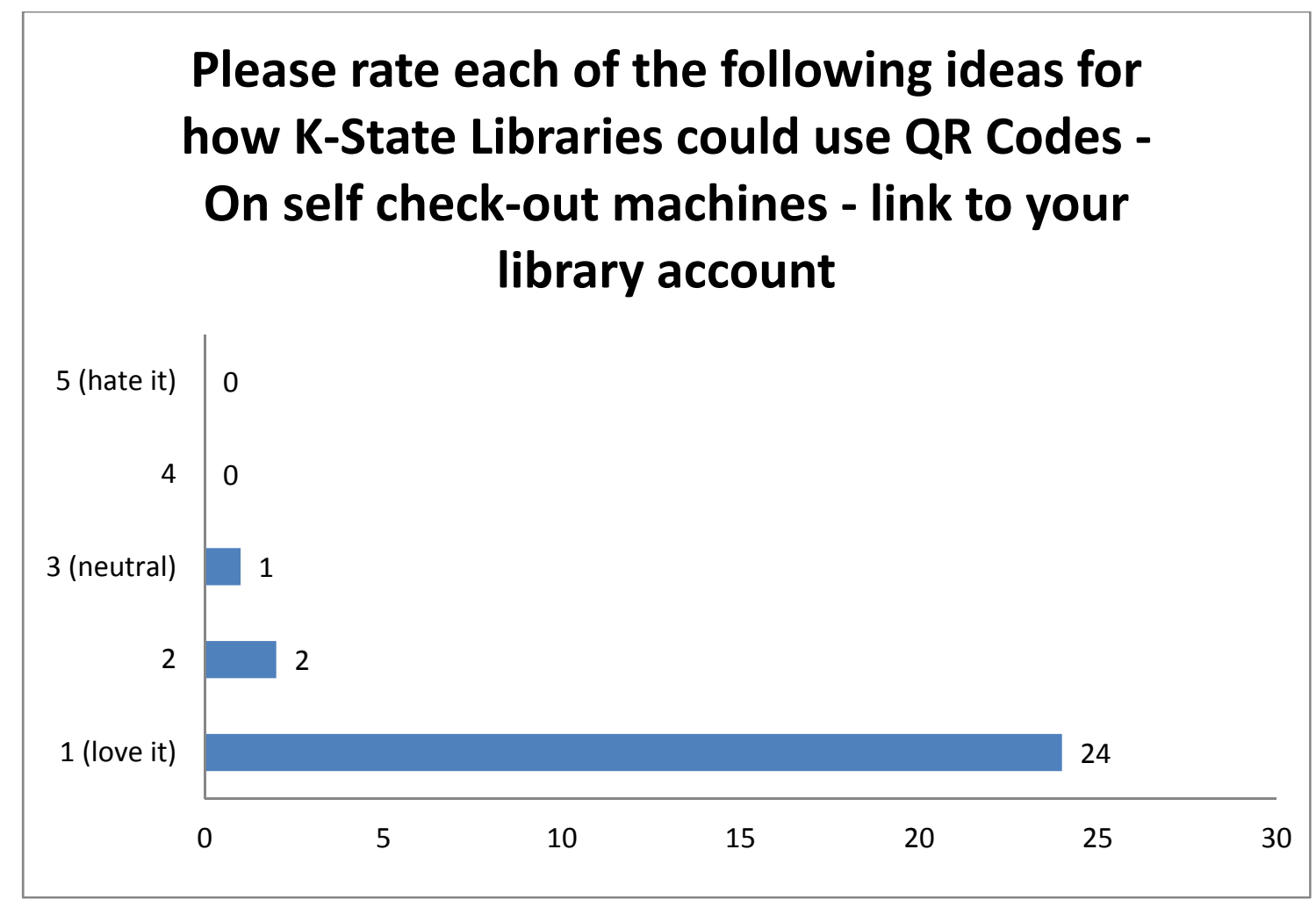

Figure 8

\section{Please rate each of the following ideas for} how K-State Libraries could use QR Codes On stacks/books/journals - link to related digital resources

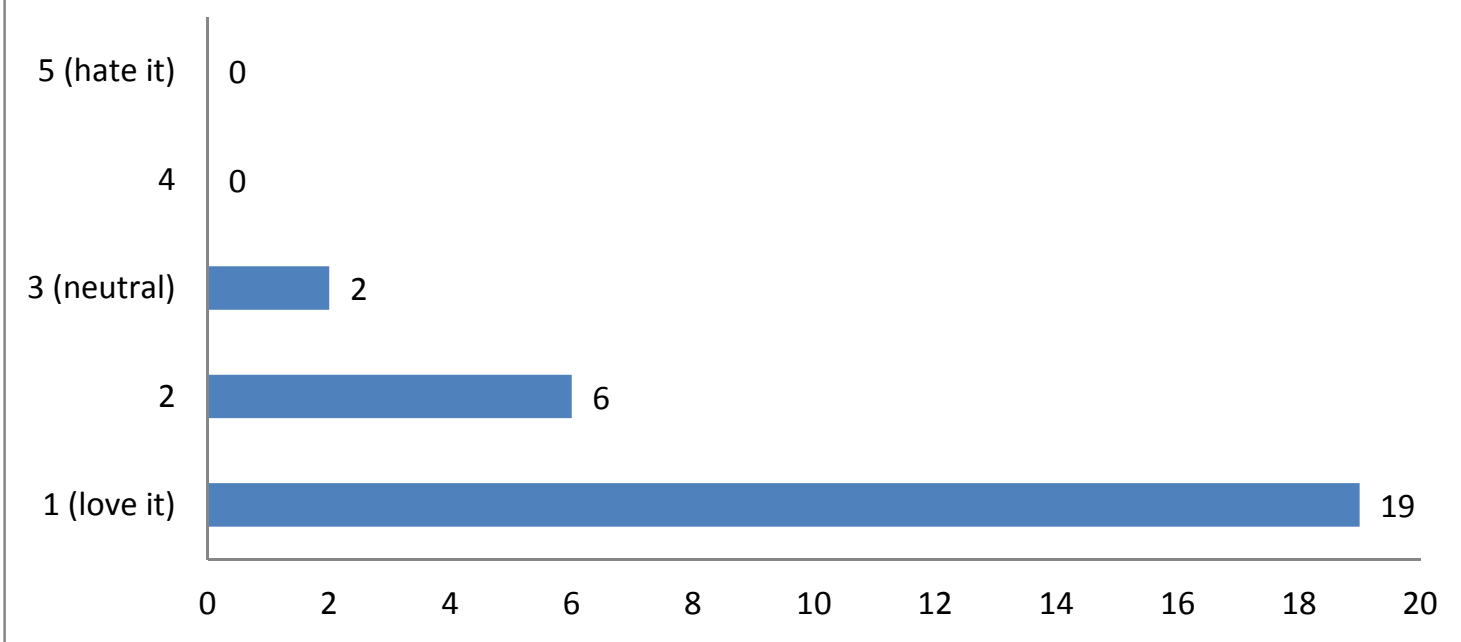

Figure 9 


\section{Study 2: QR code sign pilot}

The 40 QR code signs were displayed in Hale Library for three weeks. During this period, there were 91 instances when one of the QR codes was scanned and three instances when one of the short urls was visited. Of the 91 QR code scans, 59 (64.8\%) were of the code next to the text 'See a building map,' 24 (26.4\%) were of the code next to the text 'See the stacks guide,' and 8 8.8\%) were of the code next to the text "Contact the help desk." All of the short urls visited were next to the text "See the stacks guide."

Though it is tempting to conclude that patrons showed a strong preference for using QR codes that lead to a building map, that conclusion is not warranted. That is because the position of the codes on the signs was not varied. The patrons may simply have preferred the top QR code, regardless of its content. Though this seems unlikely, that possibility cannot be ruled out without further investigation.

Of the 40 signs, 16 (40\%) were not used by patrons: they had no scans of their QR codes or visits to their short urls. Four (10\%) of the signs had a single use, four (10\%) had two uses, six (15\%) had three uses, one (2.5\%) had four uses, four (10\%) had five uses, two (5\%) had six uses, two (5\%) had seven uses and one (2.5\%) had 10 uses. Of the top 10 most used signs, two were located in Hale Library's main elevators, one was located on the end of a set of shelves visible from the main elevators, and two were located on the ends of stacks visible from the restrooms. This pattern suggests that there is a high correlation between overall volume of traffic in an area and the likelihood of a QR code or short url being used in that area.

\section{Study 3: Focus groups}

Collectively, the five focus groups had a total of 16 participants. Two of the sessions had one participant, one had two participants, one had three, and one had nine. If our focus groups had been designed for extensive discussion and exploration of nuanced ideas and opinions, we would have found the low number of participants in several of these sessions to be problematic since the quality and breadth of ideas presented in those sessions would have been limited. Since our focus groups were primarily vehicles for gathering individual opinions and individual data, we felt that the data from all the sessions was valid for our purposes.

Segment 3: QR code sign informational content preferences. When presented with a group of four signs varying only in the type of ancillary information presented (none, short url, long url, short url+instructions), eight (50\%) of the participants expressed a preference for the sign with the short url and the instructions, four (25\%) preferred the sign with the long url, three (18.75\%) preferred the sign with the short url, and one (6.25\%) stated a preference for the sign without urls or instructions. When those who preferred the sign with instructions were asked to explain their choice, four declined to comment, three mentioned that instructions would be useful for those who had not been exposed previously to QR codes, and one said the presence of instructions conveyed friendliness. Three of the individuals who preferred the sign with the long url noted that they liked the long url because it provided information about the nature of the target of the 
QR code. The other individual who expressed this sign preference did not provide a reason. Each person who preferred the short url provided a different reason. The first liked the fact that the short url was from Google. The second liked the simplicity of the short url. The third explained that those who lack a smartphone can still benefit from the sign with a short url because they can easily write it down. The individual who preferred the sign lacking a url and lacking instructions stated that the preference was due to familiarity with QR codes. That individual stated that since many people are not familiar with them, it is best to provide instructions.

Segment 4: QR code size preferences. When presented with a group of four signs varying only in the size of the QR code, 10 (62.5\%) of participants expressed a preference for the sign with the third largest QR code, three (19\%) expressed a preference for the sign with the second largest QR code, and three (19\%) expressed a preference for the sign with the largest QR code. Six of the individuals who preferred the third largest size did not provide a reason. Three with this preference explained that it is because the larger ones are too large. The other noted that it is large enough to see from a distance but small enough to scan easily from close by. All three participants who expressed a preference for the second largest QR code gave a rationale. Two of them stated that the biggest is too distracting, but the smallest two are too hard to see. The other noted that the second largest QR code sticks out the best due to proportions of the sign. All three of the participants who preferred the largest QR code also offered reasons. Those reasons were that it is the easiest to see from a distance, because it catches ones attention, and because multiple people could scan it simultaneously.

During the discussions with the participants a few noted that it is difficult to make this assessment out of context. They argued that the optimal size would depend largely on where the sign was placed and whether there were other objects in the environment competing for attention. Given these comments and the reasons expressed for the size preferences, it seems appropriate to conclude that large QR codes should be employed in areas where the sign itself might be inconspicuous or lost in a sea of other visual distractions. Smaller QR codes can be used in places where individuals will be approaching the sign in the course of accomplishing other tasks, e.g., printing or scanning.

Segment 5: QR code color preferences. Only nine of the 16 participants were presented with the set of signs varying only in the color of the QR code. Of those nine, five (56\%) indicated a preference for the purple code, three (33\%) a preference for the code with gold on purple, and one $(11 \%)$ a preference for the black on white code. Only four of the participants provided a reason for their preference. Each of those four preferred the purple QR code because purple is one of Kansas State University's official colors.

Segment 6: Timing study. Three participants elected not to participate in the QR code timing study and two elected not to participate in either of the url entry timing studies. The average time required to scan the $\mathrm{QR}$ code and see the target page load was 8 seconds $(\mathrm{n}=13)$. The average time it took to type in the short url and see the target page load was 24 seconds ( $\mathrm{n}=14)$. The 
average time needed to type in the long url and see the target page load was 82.5 seconds ( $\mathrm{n}=14$ ). It is important to note that each participant's QR code scanning time did not include time required to launch a QR code reader and each participant's url entry time did not include time required to launch a web browser. However, even if one were to assume that the time required to find and launch a previously installed QR code reader were a few seconds longer than the required to find and launch a web browser, the QR code scanning operation would still enjoy a robust time advantage over url typing.

Segment 7: Questions. Eleven of the participants told us that they had never before scanned a QR code. The other five stated that they had. One of those exclaimed that they are "fast and fun and I love the interactivity.” Nine participants responded when we asked them if they could think of any activities they might want to do with QR codes in the library. Four of those responses were that they would like to use QR codes to invoke a map that would show their current location. Two others expressed a desire for QR codes that would support wayfinding. One of those individuals wished for the ability to find good study spaces via a QR code and the other asked for a QR code that would help him find a particular brand of soda. Three of the participants explained that it would be helpful to have QR codes that would help them find books. Two of those wished for help finding recommendations for books on a variety of subjects and the other wanted a way to use a QR code to see a list of new books.

Several of the questions asked participants for their thoughts about potential uses of QR codes in libraries. Below is a list of each potential use followed by a brief summary of the responses.

A way for patrons to view DVD trailers. Fourteen participants provided an opinion about this potential use. Ten of the 14 simply stated that they would use such a QR code. One said they might use them. One said they would use them only if they were interested in a particular DVD. One noted a preference for a QR code that would show the location of a DVD rather than present a trailer. One person claimed that they would "scan them avidly."

A way for patrons to call a librarian. Only one of the thirteen participants who provided an opinion about this potential use expressed interest in using a QR code for this purpose. Eleven said they would prefer to have the sign simply show them the phone number. Two indicated they would like the sign to show a map that identifies the location of a help desk.

A way to view videos showing how to use equipment such as a printer. Nine of the thirteen participants who provided an opinion about this potential use stated that they would use QR codes for this purpose. Four said they would not use a QR code to watch a video tutorial. Three of those four noted that it would be better to simply present text instructions on a sign. The other suggested that the video continually loop on a monitor near the equipment. 
A way for patrons to see a list of books related to the one whose QR code is scanned. Each of the thirteen individuals who provided an opinion about this potential use simply stated that they like this idea.

A way to view maps showing how to get from the current location to various destinations. Each of the five individuals who provided an opinion about this potential use said they would use QR codes for this purpose. One of those five noted that it would be helpful to have the maps include arrows showing the location of the destination.

A way for patrons to access a blog they could use to provide general feedback about the library. Each of the ten individuals who provided an opinion about this potential use said they like this idea.

The question segment concluded with two final questions. Each of the 11 participants who responded to the question, "how likely would you be to use QR codes in the library?" stated that they would use them. One qualified that response by expressing a preference for QR codes that would help find books. Four participants provided us with additional suggestions. In brief, those suggestions were to (1) display QR codes in a formal, fancy manner; (2) make sure that all targets of a QR code are mobile friendly; (3) publish news about QR codes so that patrons know what they are; and (4) create online exhibits to let patrons know what types of books we have and use QR codes to link to those online exhibits.

\section{Conclusions and future directions}

Several conclusions can be drawn from our students' responses:

1. Our respondents find it easy to use QR codes.

2. In order to appeal simultaneously to the full spectrum of preferences voiced in this study, the design of the QR code should:

a. provide a short url to appease those who wish to jot something down,

b. a long url to provide insight into the nature and trustworthiness of the target, and

c. instructions to make the technology accessible to those who are unfamiliar with the technology.

The key to this design would be to make the instructions succinct and to use color and/or spacing to visual separate the three ancillary elements from one another.

3. Many of the responses on the potential uses of QR codes suggest that our students would like to see a stronger connection between the physical library and the virtual one.

4. Students are interested in QR codes for their ability to help them more easily and more quickly accomplish tasks that are of value to them. QR codes that do not meet an extant need are not likely to be scanned. 
As mobile technologies continue to evolve at a rapid speed, it is likely that tools to link the physical and the virtual, such as QR codes, will become both more sophisticated and intuitive to use. Our studies provide us a framework to assess not only the usage of QR codes but also how our patrons prefer to use their mobile devices and what the libraries could provide on that platform. Librarians must interrogate their assumptions about what technologies users might find useful. Rather than call upon anecdotes or appeal to only users "like us," we should take the simple step of actually talking to them about what they do and do not like about a technology.

Further studies on tools other than QR codes on a variety of mobile devices would be a useful way to gain more insight into how libraries can take advantage of mobile communication to provide services to patrons. Two mobile technologies that have potential to greatly augment patrons' experiences of the library are Near Field Communication and location-based Augmented Reality. Near Field Communication requires that chips be placed in objects and that mobile devices be equipped to communicate with those chips. As the mobile device approaches a chip, the device could display information transmitted by the chip. This would allow users to passively consume virtual information that is embedded into the environment. Location-based Augmented Reality devices display information that is related to three-dimensional location and point-of-view. Google Glass is one example of this technology that is currently generating interest and concern. As libraries consider how to respond to these new technologies, it is vital that they base decisions on users' actual needs and not on librarians' desires to insert the technology into every potential virtual nook and cranny. 


\section{Appendix One}

QR Code Survey

\section{QR Codes in the Library}

Congratulations! You have successfully scanned a QR code! QR codes are a great way to link the physical world to the digital world. Please complete the survey below and let us know how you might like us to link our physical library to our digital resources using QR codes. This four question survey is intended to gather information about your experience with QR codes and your opinions about their usefulness for KState Libraries. Your participation is completely voluntary. If you choose to complete the survey, we estimate that it will take you 2-3 minutes to finish it. You may skip any (or all) of the questions on the survey, if you wish. Your responses will be completely anonymous.

On a scale of 1 to 5 , with 1 being very easy, rate how easy it was for you to get to this page via this QR code:

$\begin{array}{lllll}1 & 2 & 3 & 4 & 5\end{array}$

easy $\mathbb{C} \quad \mathbb{C} \quad \mathbb{C} \quad \mathbb{C}$ hard

Were there any challenges to using this QR code? If yes, please explain

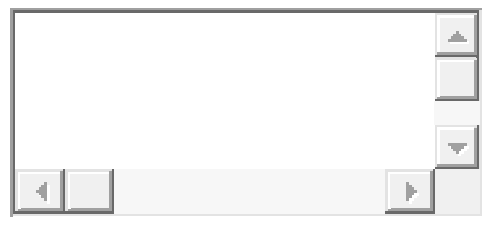

Please rate each of the following ideas for how K-State Libraries could use QR Codes
1 (love it)
3 (neutral) 4
5 (hate it)

On DVD cases - link to movie trailers

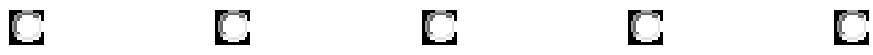


1 (love it) $2 \quad 3$ (neutral) $4 \quad 5$ (hate it)

On equipment (e.g., microform machines) link to tutorials on how

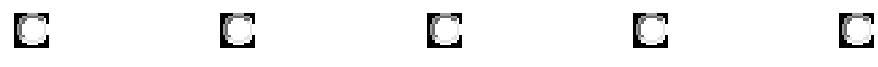
to use them

In various library

locations: link to self-

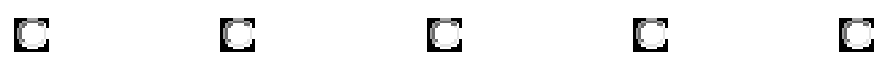

guided library tour

On self check-out machines - link to your library account

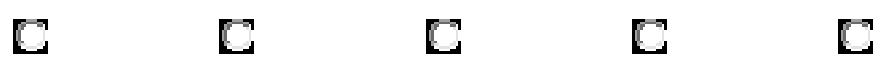

On stacks/books/journals link to related digital resources

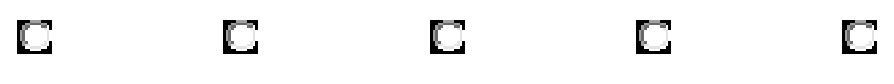

Any other comments or suggestions about how K-State Libraries should use (or not use) QR codes?

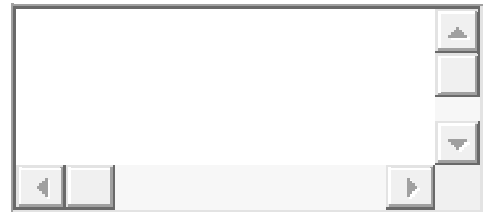


Appendix Two

QR code sign with a short url and instructions

\section{Interested in Basketball?}

Check out our blog about the history of basketball here at K-State:

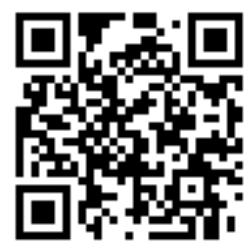

goo.gl/4ZFMA

Scan this QR code to get this blog post on your mobile device.

Don't have a QR code reader? Download one from your app store.

*Standard data plan fees may apply 


\section{References:}

Barber, J. (2009), “View from inside the QR world.” The Seybold Reporter, Vol. 9 No. 21, p.12.

Comscore (May 2012), “Do QR codes work best in magazines and newspapers?”, available at: http://www.comscoredatamine.com/2012/05/do-qr-codes-work-best-in-magazines-andnewspapers/ (accessed 2 May 2013).

Comscore (Dec. 2011), ”20 million Americans scanned a QR code in October”, available at: http://www.comscoredatamine.com/2011/12/20-million-americans-scanned-a-qr-code-inoctober/ (accessed 2 May 2013).

Denso Wave Incorporated. (n.d.), “History of QR Code”, available at: http://www.qrcode.com/en/history/ (accessed 2 May 2013).

Elmore, L., Stephens, D. (2012). “The Application of QR Codes in UK Academic Libraries”, New Review of Academic Libraries, Vol. 18, No. 1, pp. 26-42.

Hampton, D. , Peach, A., and Rawlins, B. (2012), “Extending library services with QR Codes”, The Reference Librarian, Vol. 53, No.4, pp. 403-414

MacDonald, S. (2012), “Implementation of QR Codes at Indiana University’s Fine Arts Library”, Journal of the Art Libraries Society of North America, Vol. 31, No. 2, pp. 276-284.

Pulliam, B., and Landry, C. (2010), “Tag, you're It! Using QR codes to promote library services”, The Reference Librarian, Vol. 52, No.1-2, pp. 68-74

Shin, D., Jung, J., and Chang, B..(2012), “The psychology behind QR codes: User experience perspective”, Computers in Human Behavior, Vol. 28, pp.1417-1426.

Walsh, A. (2011), "Blurring the boundaries between our physical and electronic libraries: Location aware technologies; QR codes and RFID tags”, The Electronic Library, Vol. 29, No. 4, pp. 429-437.

Whitchurch, M.J. (2012), “A quick response: QR code use at the Harold B. Lee Library”, The Reference Librarian, Vol. 53, No.4, pp. 392-402.

Wisniewski, J. (2010), “Bridging the other digital divide”, Online Vol. 34, No. 5, pp. 55-57.

\section{Further Reading:}

Comscore (Sept. 2012), "QR code usage smong European smartphone owners doubles over past year.”, available at http://www.comscore.com/Insights/Press_Releases/2012/9/

QR_Code_Usage_Among_European_Smartphone_Owners_Doubles_Over_Past_Year (accessed 2 May 2013). 
eMarketer (2012), "Forecast: Number of smartphone users in the U.S. 2010-2016" eMarketer,. available at http://www.emarketer.com/Article/Smartphones-Continue-Gain-Share-US-MobileUsage-Plateaus/1008958\#qMG4uXolkB1rtswk.99 (accessed 2 May 2013).

Ramsden, A., and Jordan, L. (2009), “Are students ready for QR codes? Findings from a student survey at the University of Bath.” Working Paper. University of Bath, available at: http://opus.bath.ac.uk/12782/ (accessed 2 May 2013).

Walsh A. (2010), "QR Codes - using mobile phones to deliver library instruction and help at the point of need”, Journal of Information Literacy, Vol. 4, No. 1, pp., 55-64. http://ojs.lboro.ac.uk/ojs/index.php/JIL/article/view/PRA-V4-I1-2010-4 (accessed 2 May 2013).

Wells, V. (2012), “Hunting for QR Codes: Linking students to the music collection”, Music Reference Services Quarterly, Vol. 15, No. 3, pp. 137-148.

Yarmey, K., and Swartz, T. (2012), “Augmenting a science center's reality: A QR code project”, The Reference Librarian, Vol. 53, No. 4, pp. 384-391. 